\title{
Minor and giant omphalocele: long-term outcomes and quality of life
}

\author{
Floortje C. van Eijck ${ }^{a, *}$, Yvonne L. Hoogeveen ${ }^{b}$, Chris van Weel ${ }^{c}$, \\ Paul N.M.A. Rieu ${ }^{d}$, Rene M.H. Wijnen ${ }^{d}$
}

${ }^{a}$ Department of Surgery, Erasmus Medical Center, Rotterdam 3000 CA, The Netherlands

${ }^{\mathrm{b}}$ Department of Radiology, Radboud University Nijmegen Medical Center, Nijmegen 6525 GA. The Netherlands

${ }^{\mathrm{c}}$ Department of General Practice, Radboud University Nijmegen Medical Center, Nijmegen 6525 GA, The Netherlands

${ }^{\mathrm{d}}$ Department of Pediatric Surgery, Radboud University Nijmegen Medical Center, Nijmegen 6525 GA, The Netherlands

Received 29 May 2008; revised 1 October 2008; accepted 4 November 2008

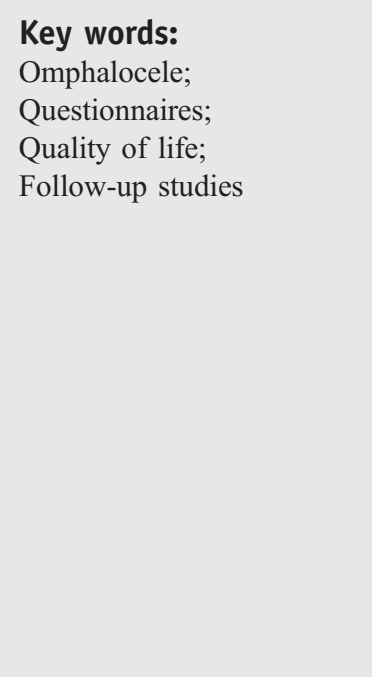

\begin{abstract}
Purpose: Long-term outcome and quality of life in omphalocele (OC) studies are mainly focused on cosmetic disorders with the abdominal scar and gastrointestinal disorders. The aim of this study was to compare long-term mortality, morbidity, and quality of life between patients with minor and giant OCs. Methods: Records of 89 minor and 22 giant OC children were reviewed. A questionnaire on general health was sent to all patients. A second questionnaire concerning quality of life and functional status; Darthmouth COOP Functional Health Assessment Charts/WONCA (COOP/WONCA) was sent to all patients aged 18 years or older and a peer control group.

Results: Of the surviving patients (69 minor OC, 20 giant OC), 12 were lost to hospital follow-up. The first questionnaire was returned by $64(83 \%)$ of 77 patients. There were no significant differences in gastrointestinal disorders. Cosmetic problems were experienced significantly more in giant OC. The results of the COOP/WONCA charts indicated a good to very good quality of life in both groups comparable to the control group.

Conclusions: Our study indicates that after a high level of medical intervention perinatally, quality of life is good to very good in both groups and comparable to healthy young adults.
\end{abstract}

(C) 2009 Elsevier Inc. All rights reserved.
Omphalocele (OC) is a congenital abdominal wall defect at the site of the umbilical ring with evisceration of the bowel covered by a 3-layered membrane of peritoneum, Wharton's jelly and amnion. It is associated with other congenital anomalies in up to $77 \%$ of patients. Omphalocele can be approximately divided into 2 groups as follows: minor and major (giant). In minor OC, the abdominal wall defect is

* Corresponding author. Tel.: +31 644511079; fax: +31 243613547.

E-mail address: fcvaneijck@gmail.com (F.C. van Eijck). relatively small $(\leq 4 \mathrm{~cm})$ and can generally be managed by primary closure. Giant OC is defined as abdominal wall defect of at least $5 \mathrm{~cm}$ and liver included [1-4]. It is associated with an underdeveloped abdominal cavity and a high degree of visceroabdominal disproportion that prohibits safe primary closure.

Before the $1970 \mathrm{~s}$, up to $80 \%$ of neonates died of starvation and associated complications in the postoperative period as a result of prolonged intestinal ileus [5-8]. The development of total parenteral nutrition and staged methods 
of closure in the late 1970s contributed to an increased rate of survival. Morbidity and mortality are still high in OC (up to $30 \%$ ), and in case of chromosomal abnormalities, which are more common in minor OC, these are even higher [9]. Koivusalo [10] showed in patients born up to 1980 that after the first year the morbidity and quality of life are similar in comparison with the general population. In the area of prenatal sonography, $\mathrm{OC}$ can be detected at the second trimester ultrasonographic scan. A diagnosis of $\mathrm{OC}$ is almost always followed by amniocentesis and chromosome analysis. A Norwegian study reported more than $50 \%$ pregnancy terminations in case of chromosomal anomalies [11]. Even in case of isolated omphalocele, termination is still high (37\%) $[11,12]$. However, the question arises if this should be advocated for all patients with an OC, or is there a need to differentiate between minor and giant OCs?

Long-term outcome seems to be the most important issue for parents [13]. Upon this early diagnosis, it is essential to inform the parents concerning morbidity, mortality, and quality of life later in life.

The aim of our study was to retrospectively evaluate the long-term morbidity and quality of life in a group of pediatric patients treated for $\mathrm{OC}$ and to compare the outcomes of patients with minor vs giant $\mathrm{OC}$.

\section{Patients and methods}

Between 1971 and 2004, 111 patients with OC were treated at the Radboud University Medical Center in Nijmegen, the Netherlands. All medical records were reviewed. Minor $O C$ was defined as abdominal wall defect $4 \mathrm{~cm}$ or less; giant $O C$ was defined as abdominal wall defect of at least $5 \mathrm{~cm}$ and liver included.

Patients were treated either surgically, receiving standardized perioperative care, including mechanical ventilation and total parenteral nutrition if necessary, or nonoperatively by covering the $\mathrm{OC}$ after birth with dry sterile dressings until fully epithelialized. In case of infection of the OC, specific wound dressings available at that time were used. Nonoperative treatment was performed in case of contraindications for surgical repair or in case of a giant OC in which epithelialization was the primary goal. Those who survived in the nonoperated group were not operated upon later in life for correction of the abdominal wall.

To evaluate long-term outcomes, a questionnaire on general health and nonoperative and postoperative outcomes was sent to all surviving patients. Parents completed the questionnaire for patients younger than 8 years and assisted children between 8 and 12 years. Those older than 12 years completed the questionnaire themselves or with support of their parents. The questionnaire consisted of 4 sections as follows: health/disease, gastrointestinal and urogenital disorders, cosmetic results, and social functioning (Table 1).

The Darthmouth COOP Functional Health Assessment Charts/WONCA (COOP/WONCA) was sent to all young
Table 1 Questionnaire (divided into 4 sections)

\begin{tabular}{ll}
\hline Section & Questions \\
\hline Health/disease & $\begin{array}{l}\text { General health, stature and weight, use of } \\
\text { medication, pulmonary complaints, operations } \\
\text { or hospitalization after initial treatment } \\
\text { Incidence and frequency of chronic abdominal } \\
\text { complaints, abdominal pain, constipation, } \\
\text { diarrhea, nausea, vomiting, bowel habit, and } \\
\text { use of a special diet }\end{array}$ \\
Cosmetic & $\begin{array}{l}\text { Previous ventral hernia and surgery, presence, } \\
\text { or absence of umbilicus }\end{array}$ \\
results & $\begin{array}{l}\text { Abdominal scar and umbilicus: cosmetic } \\
\text { problems, cosmetic surgery performed, or wish } \\
\text { for cosmetic surgery to improve the results }\end{array}$ \\
Social & $\begin{array}{l}\text { Subjects as relationship-related problems, } \\
\text { choices with regard to school and profession, } \\
\text { tynctioning of education undertaken, present } \\
\text { profession, and any sporting activities }\end{array}$ \\
\hline
\end{tabular}

adults aged 18 years or older. This questionnaire, validated for adults, represents functional status and quality of life and appears to have low susceptibility to cultural differences [14]. The COOP-WONCA charts were initially developed and tested by the Dartmouth COOP Project and were translated and further tested in collaboration with the World Organization of National Colleges, Academies, and Academic Associations of General Practitioners/Family Physicians (WONCA). The COOP/WONCA charts measure 6 core aspects of functional status as follows: physical fitness, feelings, daily activities, social activities, change in health, and overall health. Each item is rated on a 5-point ordinal scale ranging from 1 ("no limitation at all") to 5 ("severely limited"); "for change in health," score 1 indicates "much better" and score 5 "much worse" [14-18].

For peer group reference, the COOP/WONCA charts were also completed by a control group of healthy young adults $(\mathrm{n}=100)$. The control group consisted of males and females aged between 18 and 25 years, chosen at random from the patient registers of 2 general practitioners in the Netherlands, with one located in a city of 120,000 inhabitants and the other in a small country town.

This study was approved by the Institutional Review Board of the Radboud University Nijmegen Medical Center.

Statistical analyses were performed using SPSS 16.0 (SPSS Inc, Chicago, Ill). A $\chi^{2}$ test was used to analyze the statistical difference between compared groups. A $P$ value of less than .05 was considered statistically significant.

\section{Results}

The OC patient group $(\mathrm{n}=111)$ consisted of $89(80 \%)$ minor OC and $22(20 \%)$ giant OC. Associated congenital anomalies were identified in $57(51 \%)$ patients, including Beckwith-Wiedemann syndrome $(\mathrm{n}=12)$; trisomy 13,18 , 
and $21(\mathrm{n}=9)$; cardiovascular disorders $(\mathrm{n}=9)$; pentalogy of Cantrell $(\mathrm{n}=5)$; pulmonary hypertension $(\mathrm{n}=3)$; pulmonary hypoplasia $(\mathrm{n}=3)$; Vertebral anomalies, Anal atresia, Cardioavascular anomalies, Tracheoesophageal fistula, Esophageal atresia, Renal or radial anomalies, preaxial Limb anomalies association $(\mathrm{n}=1)$; and Omphalocele, Exstrophy of the cloacae, Imperforate anus, Spinal abnormalities $(\mathrm{n}=$ $1)$. These congenital anomalies were clearly more present in minor OC (55\% vs $36 \%)$.

Of the 111 patients with omphalocele, $22(20 \%)$ patients died - 7 patients in less than 36 hours because of multiple congenital anomalies, 12 died within 1 year (5 congenital anomalies, 2 pulmonary hypoplasia, 3 pulmonary hypertension, 1 sepsis, 1 acute respiratory distress syndrome), and 3 died after 1 year but before 8 years $(2$ aspiration, 1 postoperative sepsis). Only $2(9 \%)$ of the 22 deceased patients had giant $\mathrm{OC}$, one because of pulmonary hypoplasia. There was no significant difference in mortality between the 2 groups $(P<.159)$. The deceased patients were excluded from further evaluation.

Of the 89 surviving patients, 20 (22\%) were giant OC and 69 (78\%) minor OC. The overall median hospital stay was 12 days (range, 2-226 days).

The questionnaire on general health and postoperative outcomes was sent to 77 of the 89 surviving patients (12 lost to hospital follow-up). The response rate was 64 $(83 \%)$ of 77 patients, of which $16(25 \%)$ patients were giant OC. The median age of the patients at the time of the survey was 11.3 years (range, 1-25 years) for giant OC and 16.7 years (range, 3-32 years) for minor OC.

Questionnaire outcomes are as follows:

(1) Health/disease: Readmission to hospital occurred 32 times in $11(69 \%)$ giant OC and 48 times in $33(69 \%)$ minor OC. The most frequent operations were inguinal hernia correction $(\mathrm{n}=20)$ and for ear-nose-throat problems $(n=13)$ (tonsillectomy, paracentesis and ear tubes, nasal polyps). Other operations included surgery for associated anomalies, fundoplication, small bowel obstruction, correction of malrotation, orchidopexy, hernia cicatricialis, cosmetic surgery of the abdominal wall, abdominal scar, and creating a new umbilicus, hip operation, and eye operation.

Medication was still used by 20 patients (31\%) (6 giant OC [37\%], 14 minor OC [29\%]). The most frequent being pulmonary medication (3 giant OC [19\%], 8 minor OC [17\%]) or medication for chronic constipation (2 giant OC [13\%], 2 minor OC [4\%]).

At readmission and/or operation, the age of the patient varied from 1 month to 23 years.

(2) Gastrointestinal disorders (GI): GI disorders are given in Fig. 1. A quarter $(n=4)$ of the giant $\mathrm{OC}$ and $15 \%$ $(n=7)$ of the minor OC mentioned GI disorders with a frequency of more than 4 times a month. Abdominal pain was reported in 33\% of minor OC and in $19 \%$ in giant OC. This was not significant $(P=.27)$. Special diet because of allergies was used in $13 \%$ giant OC vs $4 \%$ in minor OC (n.s., $P=.23$ ).

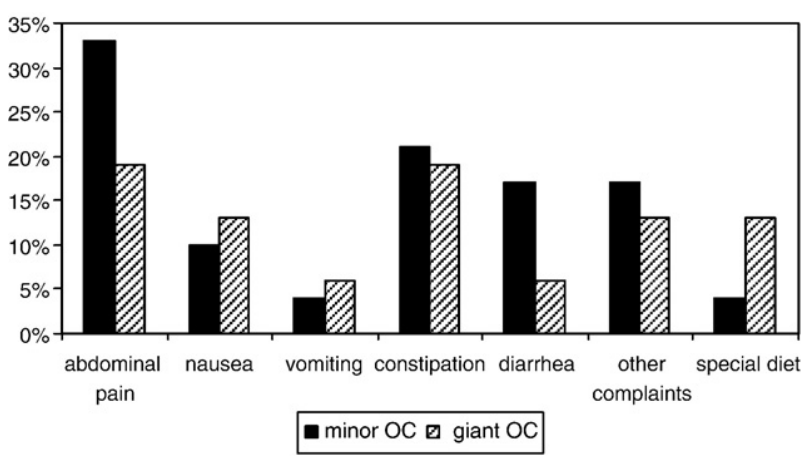

Fig. 1 Long-term abdominal complaints in patients with minor and giant OC. No significant differences were found between the 2 groups.

(3) Cosmetic results: Cosmetic problems with abdominal scar were present in 7 (44\%) of 16 giant OC (median age, 12 years; range, $2-20$ years) and in $9(19 \%)$ of the 48 minor OC (median age, 19 years; range, 1-29 years) responders, all of whom desired a correction by cosmetic surgery. These cosmetic problems were significantly more present in giant OC $(P<.05)$. Three patients had already undergone cosmetic surgery to improve the scar, and one patient had reconstruction of the umbilicus.

Of the 6 ( 3 males and 3 females) (38\%) giant OC with an umbilicus, $2(33 \%)$ patients expressed satisfaction. Of the 21 (13 males and 8 females) (44\%) minor OC with an umbilicus, $14(67 \%)$ patients expressed satisfaction. This was not significant between the 2 groups $(P=.14)$. All giant OC without an umbilicus $(\mathrm{n}=10)$ indicated dissatisfaction with missing the umbilicus $(P<.001)$, with one third desiring reconstructive surgery. In the group of 27 minor OC without an umbilicus, 10 (37\%) indicated dissatisfaction with missing the umbilicus of who 9 desired reconstructive surgery.

(4) Social functioning: Of the 64 patients (30 males, 34 females), 13 (5 giant OC, 8 minor OC) were primary school pupils, 6 (6 minor OC) attended special schools, 23 (5 giant OC, 18 minor OC) were in secondary education/high school, 9 (2 giant OC, 7 minor OC) attended or had studied at university, and 9 ( 1 giant OC, 8 minor OC) were permanently employed. Thirteen patients were in day care.

Only 3 ( 2 giant OC, 1 minor OC) patients ever had the feeling that their abdominal defect prevented particular choices with regard to school and profession. The abdominal wall defect influenced relationships in 10 patients (1 giant OC, 9 minor OC) (concerns about relationship, teasing). Fifty-one patients participated in sporting activities.

\subsection{Darthmouth COOP Functional Health Assess- ment Charts/WONCA (COOP/WONCA) questionnaire}

The COOP/WONCA questionnaire was sent to 23 patients aged 18 years or older and returned by 21 ( 2 giant OC, 19 minor OC) patients) (response rate, 92\%), consisting of 10 females (median age, 26 years; range, 18-28.5 years) 


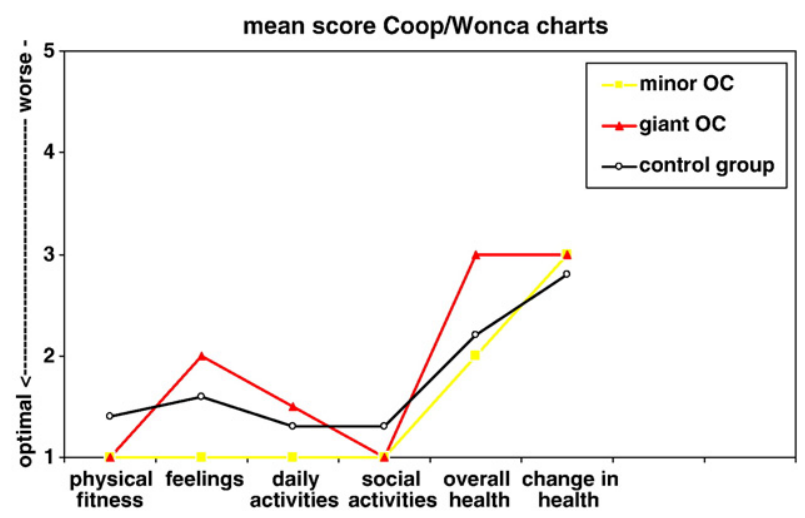

Fig. 2 Mean scores COOP/WONCA charts (minor OC vs giant OC vs control group).

and 11 males (median age, 20 years; range, 18-23.3 years). Six responders (1 giant OC, 5 minor OC) had associated anomalies ( 2 cheilo-gnatopalato-schisis, Cantrell, BW-syndrome, cardiac disorder, skeletal anomalies). Fig. 2 shows the mean scores for each COOP/WONC chart according to giant and minor OC. The median scores were similar for each chart. For both giant $\mathrm{OC}$ and minor OC, feedback indicated no change in state of health (scale 3 ) during the last 2 weeks. Overall health was generally rated good in the giant $\mathrm{OC}$ to very good in the minor OC. Physical and emotional health did not appear to limit social activities in both groups; minor OC scored no problems on feelings and daily activities, whereas giant $\mathrm{OC}$ were only slightly bothered on feelings and daily activities. The responses given in the questionnaire by our patient group indicate that associated anomalies did not influence quality of life.

Of the COOP/WONCA charts sent to 210 young adults (age/sex matched) for the control group, 100 were returned (response rate $48 \%$ ). Compared to the patient group, there were no clear differences in the scores for each chart. The minor OC even scored slightly better than the control group.

\section{Discussion}

New developments in treatment and neonatal care after 1970 have led to higher survival rates of neonates with OC, which could be of influence on the quality of life in OC. Our retrospective long-term follow-up study, a first to be performed in a large group of children with OC exclusively, found that OC (minor and giant OC) patients as young adults ( $\leq 28.5$ years) achieve a state of health and quality of life comparable to that of general population peers. The only significant difference was the presence of cosmetic problems in giant OC.

Main causes for readmission to hospital of our patients were general surgical procedures unrelated to the preexisting OC. Gastrointestinal disorders were common in our series $(40 \%)$. Up to $30 \%$ of the patients mentioned periods of chronic abdominal pain with no significant difference between minor and giant OC. Lindham et al [19] reported similar results $(27 \%)$, although their patient group was younger ( 8.8 years). This indicates that chronic abdominal pain is not restricted to childhood but plays an important role even in (young) adulthood.

Cosmetic issues with the abdominal scar and absence of the umbilicus appear to be important from the responses given by more than half of our patient group with ages between 20 and 30 years. Preservation of the umbilicus at primary closure might give superior cosmetic results and patient satisfaction [10]. However, almost all the patients with a giant $\mathrm{OC}$ were not satisfied with the cosmetic result compared to one third of the patients with a minor OC, independent of preservation of the umbilicus. Overall the satisfaction with the cosmetic result was significantly better in the minor OC group.

Studies by Tunell et al [20] and Koivusalo et al [10] present results of long-term morbidity and quality if life in patients with gastroschisis and OC born between the periods 1948 and 1980 and 1975 and 1984, respectively. Both studies concluded that most patients (median follow-up was 26.5 [range, 17-48 years] and 14.2 years [range, 10-20 years], respectively) with abdominal wall defects are healthy adults with few or no factors restricting their activities or decreasing their quality of life. Our study involving patients treated from 1971 to 2004, shows general agreement with these 2 studies in that we found a good to very good quality of life in young adults with OC but then exclusively in minor and giant OC patients and a quality of life as good as our aged matched control group. We compared the educational level of our study group with the Dutch national population and concluded that no difference existed, with respectively $43 \%$ and 34\% having attended or studied at university [21].

Our study indicates that after a high level of medical intervention in early life, minor and giant OC patients report similar long-term results except for the cosmetic problems mentioned more serious in giant OC. However, this did not influence quality of life in either group and is comparable to that of healthy young adults. With the latter positive prospect in mind, expectant parents with fetal diagnosis of OC and parents of newborns with OC should be informed that the high burden of (surgical) interventions their child will need to undergo will likely yield a good health status in the long-term, especially when there are no associated anomalies.

\section{References}

[1] Lee SL, Beyer TD, Kim SS, et al. Initial nonoperative management and delayed closure for treatment of giant omphaloceles. J Pediatr Surg 2006;41:1846-9.

[2] Pelizzo G, Maso G, Dell'Oste C, et al. Giant omphaloceles with a small abdominal defect: prenatal diagnosis and neonatal management. Ultrasound Obstet Gynecol 2005;26:786-8.

[3] Pereira RM, Tatsuo ES, Simoes E Silva AC, et al. New method of surgical delayed closure of giant omphaloceles: Lazaro da Silva's technique. J Pediatr Surg 2004;39:1111-5. 
[4] Towne BH, Peters G, Chang JH. The problem of "giant" omphalocele. J Pediatr Surg 1980;15:543-8.

[5] Venugopal S, Zachary RB, Spitz L. Exomphalos and gastroschisis: a 10-year review 60. Br J Surg 1976;63:523-5.

[6] Jones PG. Exomphalos (syn. omphalocele). A review of 45 cases. Arch Dis Child 1963;38:180-7.

[7] Knutrud O, Bjordal RI, Ro J, et al. Gastroschisis and omphalocele. Prog Pediatr Surg 1979;13:51-61.

[8] Mahour GH, Weitzman JJ, Rosenkrantz JG. Omphalocele and gastroschisis. Ann Surg 1973;177:478-82

[9] Garne E, Rasmussen L, Husby S. Gastrointestinal malformations in Funen county, Denmark - epidemiology, associated malformations, surgery and mortality. Eur J Pediatr Surg 2002;12:101-6.

[10] Koivusalo A, Lindahl H, Rintala RJ. Morbidity and quality of life in adult patients with a congenital abdominal wall defect: a questionnaire survey. J Pediatr Surg 2002;37:1594-601.

[11] Brantberg A, Blaas HG, Haugen SE, et al. Characteristics and outcome of 90 cases of fetal omphalocele. Ultrasound Obstet Gynecol 2005;26: 527-37.

[12] Islam S. Clinical care outcomes in abdominal wall defects. Curr Opin Pediatr 2008;20:305-10.

[13] Kuppermann M, Feeny D, Gates E, et al. Preferences of women facing a prenatal diagnostic choice: long-term outcomes matter most. Prenat Diagn 1999;19:711-6.
[14] van Weel C, Konig-Zahn C, Touw-Otten FWMM, et al. Measuring functional health with the COOP/WONCA charts-a manual. Groningen: Northern Centre for Health Care Research; 1995.

[15] Bentsen BG, Natvig B, Winnem M. Questions you didn't ask? COOP/ WONCA Charts in clinical work and research. World Organization of Colleges, Academies and Academic Associations of General Practitioners/Family Physicists. Fam Pract 1999;16:190-5.

[16] Lindegaard PM, Bentzen N, Christiansen T. Reliability of the COOP/ WONCA charts. Test-retest completed by patients presenting psychosocial health problems to their general practitioner. Scand J Prim Health Care 1999;17:145-8.

[17] Lizan TL, Reig FA, Richart MM, et al. Study on health related quality of life based on information from COOP/WONCA sheets. Med Clin (Barc) 2000;114(Suppl 3):76-80.

[18] van Weel C. Functional status in primary care: COOP/WONCA charts. Disabil Rehabil 1993;15:96-101.

[19] Lindham S. Long-term results in children with omphalocele and gastroschisis-a follow-up study. Z Kinderchir 1984;39:164-7.

[20] Tunell WP, Puffinbarger NK, Tuggle DW, et al. Abdominal wall defects in infants. Survival and implications for adult life. Ann Surg 1995;221:525-8.

[21] Verweij A, vd Lucht F. What is the current situation? Volksgezondheid Toekomst Verkenning, Nationaal Kompas Volksgezondheid Bilthoven (National Review Public Health). RIVM; 2006. 